\title{
DEMOLISHED WASTE CONCRETE POWDER AS PARTIAL REPLACEMENT OF CEMENT
}

\author{
Rahees Raihan ${ }^{1}$, Deepak C $\mathbf{C}^{2}$, Abdul Vajid ${ }^{3}$, Muhammed Sabik $\mathbf{C}^{\mathbf{4}}$ \\ ${ }^{1}$ B Tech Student, Department of Civil Engineering, EKCTC Manjeri, Kerala, India \\ ${ }^{2}$ Assistant Professor, Department of Civil Engineering, EKCTC Manjeri, Kerala, India \\ ${ }^{3} B$ Tech Student, Department of Civil Engineering, EKCTC Manjeri, Kerala, India \\ ${ }^{4} B$ Tech Student, Department of Civil Engineering, EKCTC Manjeri, Kerala, India
}

\begin{abstract}
This study deals with the Partial replacement of cement by using demolished waste concrete powder(DWCP). In developing countries like India huge quantities of demolition wastes are generated in every year. Out of which very small amount is recycled or reused. Due to strict environmental laws and lack of dumping sites in urban areas, demolished concrete waste causes disposal problems. In this study the application of recycled concrete waste in concrete block as partial replacing of cement was evaluated. The effect of age of demolished concrete in partial replacement of cement was also checked in this study. For that DWCP having age 10years, 15years, 20years and 25years were collected and concrete test blocks were casted with each WDWCP at 0 , 10,15,20,25 and 30 percentage replacement with cement. The blocks produced were tested to determine their compressive strength and split tensile strength. The result shows that up to $20 \%$ replacement of cement with DWCP, the compressive strength of concrete increasing and after that there is a sudden decrease in compressive strength. The result also shows that the age of demolished concrete powder has no significant effect on strength of concrete.
\end{abstract}

Keywords: Demolished waste concrete powder (DWCP), Cement, Compressive strength

\section{INTRODUCTION}

Construction activities worldwide are responsible for the significant amount of environmental degradation, as it consumes large amount of natural resources including renewable as well as non-renewable. Depletion of resources is a major problem in the construction sector. Huge demands of building materials adversely affect the construction costs. Excessive utilization of natural resources leads to its depletion and incorporation of waste materials in the construction process brings sustainable benefits for the construction industries as well as for the society. Accumulation of unmanaged industrial or agricultural solid waste especially in developing countries has resulted in an increased environmental concern. Recycling of such wastes as a sustainable construction material appears to be a viable solution not only to pollution problem but also an economical option in the design of green buildings.

The manufacturing of cement is an energy costly process. Therefore Portland cement has a big impact on the environment due to high release of $\mathrm{CO}_{2}$. The production of one ton of Portland cement clinker generates one ton of $\mathrm{CO}_{2}$ emission. Nowadays the cement and concrete consumption is constantly increasing and the cost of cement is also steadily increasing. Hence it is important to find new alternatives, which help to reduce environmental pollution. In this study the recycled concrete waste is used as a partial replacement material for cement. This study also aimed to find the effect of age of demolished concrete powder in partial replacement of cement.

\section{EXPERIMENTAL PROGRAM}

\subsection{Materials}

CEMENT: Cement is the most important constituent of concrete, it forms the binding medium for the discrete ingredients made out of naturally occurring raw materials and sometimes blended with industrial wastes. Cement comes in various types and chemical compositions.53 grade PortlandPozzolona cement (PPC) is used for this study Program.

FINE AGGREGATE: The material smaller than $4.75 \mathrm{~m}$ size is called fine aggregate. Natural sands are generally used as fine aggregate. It may be obtained from pits, river, lake or sea shore, but it should tree from clay and silt. Sea shore sand may contain chlorides, which may cause efflorescence and may cause corrosion of reinforcement. Angular grained sand produces, good and strong concrete because it has good interlocking property, while round grained particle of sand do not afford such interlocking. River sand was used in preparing the concrete as it was locally available in sand quarry. The specific gravity and water absorption were found to be 2.73 and $2.5 \%$ respectively.

COARSE AGGREGATE: The material retained on $4.75 \mathrm{~mm}$ sieve is termed as coarse Aggregate. Crushed stone and natural gravel are the common material used as coarse aggregate for concrete. Coarse aggregate are obtained by crushing various types of granites, schist, crystalline and lime stone and good quality sand stones. When high strength concrete is required a very tine grained granite perhaps the 
best aggregate. Concrete made with sand stone aggregate give trouble due to cracking because of high degree of shrinkage. For coarse aggregate crushed $20 \mathrm{~mm}$, normal size graded aggregate was used. The specific gravity and water absorption were found to be 2.85 and $1.0 \%$ respectively. The grading of aggregate conformed to the requirement as per IS: 383-1970.

DEMOLISHED WASTE CONCRETE POWDER (DWCP): Concrete waste was collected from demolition sites and the reinforcement bars are removed by hammering. The remaining aggregate chunks are sorted by size and these was taken to the crusher. After crushing has taken place, other particulates are filtered out through a variety of methods including hand-picking and sieving. After that the secondary crushing was performed in a Los angel's apparatus, the material is sieved through 90 micron sieve. Four samples of different ages ( 8 year,15 year,19 year and 25 years) from different sites were collected.

\subsection{Compression Test}

By definition, the compressive strength of a material is that value of uniaxial compressive stress reached when the material fails completely. The compressive strength is usually obtained experimentally by means of a compressive test. The apparatus used for this experiment is the same as that used in a tensile test. However rather than applying a uniaxial tensile load, a uniaxial compressive load is applied. The compression test is carried out on the 28 day cured moulds. The size of cube specimen is $150 \mathrm{~mm} \times 150 \mathrm{~mm} \times$ $150 \mathrm{~mm}$.

$$
\text { Compressive strength }=\frac{\text { Failure load }(\mathrm{N})}{\text { Sectional area }\left(\mathrm{mm}^{2}\right)}
$$

In this study concrete cubes were casted with partial replacement of cement by DWCP. Here DWCP having age of 10years, 15years, 20years and 25years were used with $0 \%, 10 \%, 15 \%, 20 \%, 25 \%$ and $30 \%$ replacement. The compressive strength after 28 days was found for each specimen.

\subsection{Split Tensile Strength Test}

The test specimen should be stored in a place at a temperature of $27^{\circ}+/-2^{\circ} \mathrm{C}$ for $24+/-0.5 \mathrm{hrs}$. from the time addition of water to the dry ingredients. After this period the specimen should be marked and removed from the woulds and immediately submerged in clean fresh water or saturated lime solution and kept there until taken out just prior to the test. The water or solution in which the specimen $\mathrm{s}$ are kept should be renewed every seven days and should be maintained at a temperature of $27^{\circ}+/-$ $2^{\circ}$ c.Concrete cylinder having $15 \mathrm{~cm}$ diameter $\& 30 \mathrm{~cm}$ long was used for the test.

Here concrete cylinders were casted with partial replacement of cement by DWCP. Here DWCP having age of 10years, 15years, 20years and 25years were used with
$0 \%, 10 \%, 15 \%, 20 \%, 25 \%$ and $30 \%$ replacement. The split tensile strength after 28 days was found for each specimen.

$$
\text { Split tensile strength }=2 \mathrm{P} / \Pi \mathrm{ld}
$$

Where,

P- Failure load at the cylinder

1- Length of the Cylinder

d- Diameter of the cylinder

\section{RESULTS AND DISCUSSIONS}

The concrete cube casted with partial replacement of cement by DWCP was tested for 28 days and 7 days compressive strength. The obtained results are shown in Chart-1 and Chart- 2 respectively. The 7 days and 28 days compressive strength of concrete with $0 \%$ replacement of cement was $16.02 \mathrm{~N} / \mathrm{mm}^{2}$ and $21.3 \mathrm{~N} / \mathrm{mm}^{2}$ respectively.

From Chart-1, it is observed that the 28 days compressive strength for all concrete cubes were increasing up to $20 \%$ replacement and after that there is a sudden decrement in compressive strength. The maximum compressive strength is obtained at $20 \%$ replacement of cement with DWCP.

The maximum compressive strength for 10 years DWCP was $30.67 \mathrm{~N} / \mathrm{mm}^{2}$. Similarly that of 15 years, 20 years, 25 years DWCP was $30.67 \mathrm{~N} / \mathrm{mm}^{2}, 28.89 \mathrm{~N} / \mathrm{mm}^{2}$, and $27.11 \mathrm{~N} / \mathrm{mm}^{2}$ respectively. These results suggest that the age of DWCP has no significant effect on strength of concrete.

From Chart-2, it is observed that the 7 days compressive strength for all concrete cubes were increasing up to $20 \%$ replacement and after that there is a sudden decrement in compressive strength. The maximum compressive strength is obtained at $20 \%$ replacement of cement with DWCP.

The maximum compressive strength for 10 years DWCP was $18.66 \mathrm{~N} / \mathrm{mm}^{2}$. Similarly that of 15 years, 20 years, 25 years DWCP was $20 \mathrm{~N} / \mathrm{mm}^{2}, 23.12 \mathrm{~N} / \mathrm{mm}^{2}$, and $23.11 \mathrm{~N} / \mathrm{mm}^{2}$ respectively. These results also suggest that the age of DWCP has no significant effect on strength of concrete.

The concrete cylinder casted was tested for 7 days and 28 days split tensile strength. The obtained results are shown in Chart-3 and Chart-4 respectively.

From Chart-3 and Chart-4, it is observed that the 7 days and 28 days split tensile strength for all concrete cubes were increasing up to $20 \%$ replacement and after that there is a sudden decrement in split tensile strength. The maximum split tensile strength is obtained at $20 \%$ replacement of cement with DWCP.

The maximum split tensile strength ( 7 days) for 10 years, 15 years, 20 years and 25 years DWCP was $1.458 \mathrm{~N} / \mathrm{mm}^{2}$, $1.48 \mathrm{~N} / \mathrm{mm}^{2}, 1.896 \mathrm{~N} / \mathrm{mm}^{2}$ and $2.009 \mathrm{~N} / \mathrm{mm}^{2}$ respectively. Similarly the maximum split tensile strength (28 days) for 10 years, 15 years, 20 years and 25 years DWCP was $2.305 \mathrm{~N} / \mathrm{mm}^{2}, 2.617 \mathrm{~N} / \mathrm{mm}^{2}, 2.645 \mathrm{~N} / \mathrm{mm}^{2}$ and $2.716 \mathrm{~N} / \mathrm{mm}^{2}$ respectively. 


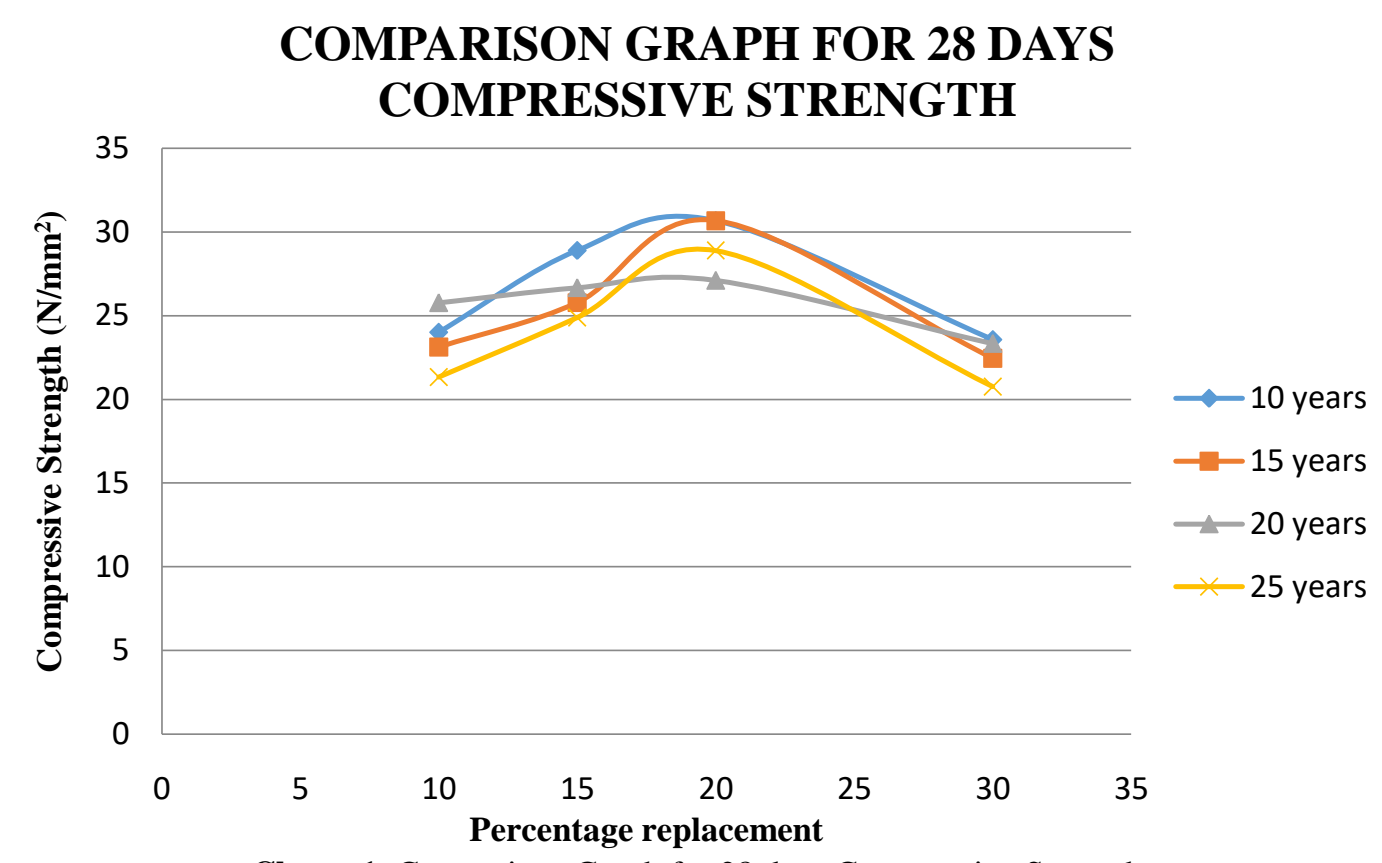

Chart -1: Comparison Graph for 28 days Compressive Strength

\section{COMPARISON GRAPH FOR 7 DAYS \\ COMPRESSIVE STRENGTH}

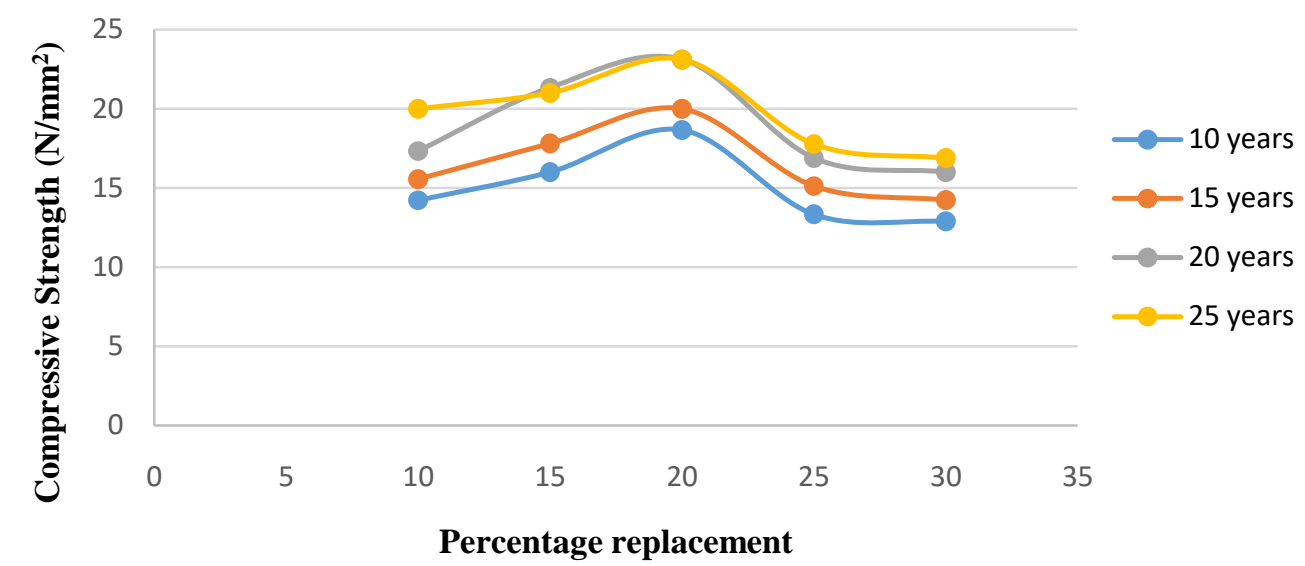

Chart -2: Comparison Graph for 7 days Compressive Strength 


\section{COMPARISON GRAPH FOR 7 DAYS SPLIT TENSILE STRENGTH}

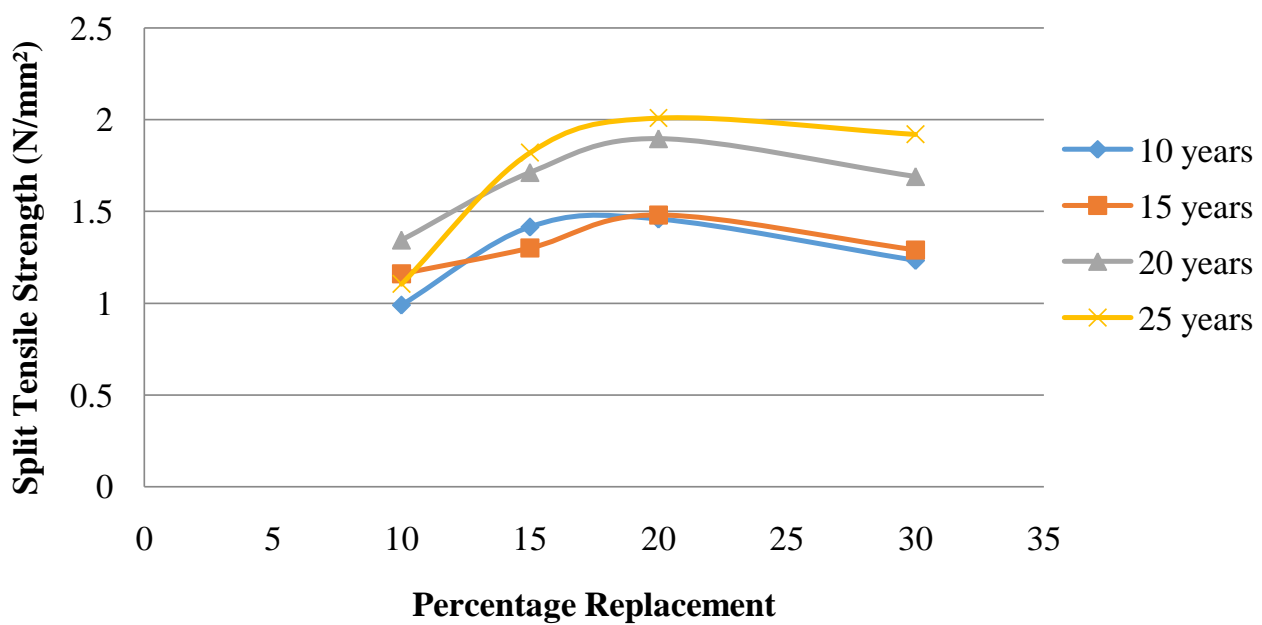

Chart -3: Comparison Graph for 7 days Split Tensile Strength

\section{COMPARISON GRAPH FOR 28 DAYS SPLIT TENSILE STRENGTH}

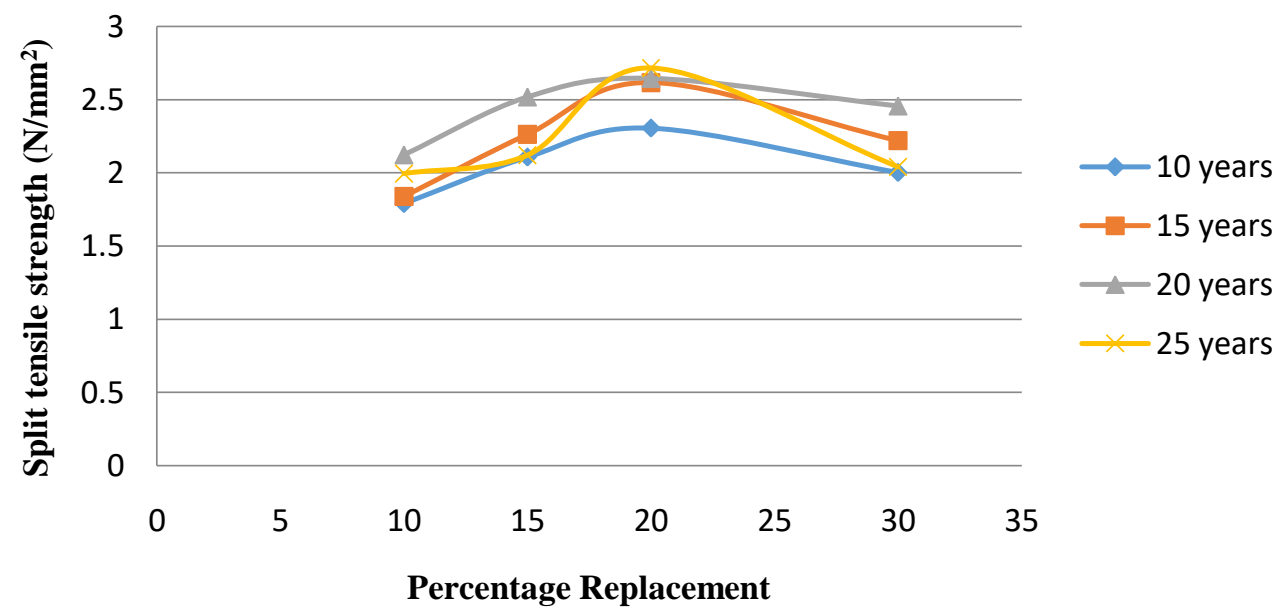

Chart -4: Comparison Graph for 28 days Split Tensile Strength

\section{CONCLUSION}

The compressive strength and Split tensile strength of all concrete is increasing up to $20 \%$ replacement of cement by DWCP and after that the strength suddenly decreasing. So $20 \%$ replacement of cement by DWCP can be suggested for construction purpose.

The age of DWCP has no significant effect on strength of concrete.

\section{REFERENCES}

[1] Yong Jic Kmi and Yun Wang Choi. Utilisation of waste concrete powder as a substitution material for cement. Elsevier 2012:30: 500-504.
[2] Jiusu L, Hanning $X$, Yong $Z$. Influence of coating recycled aggregate surface with pozzolanic powder on properties of recycled aggregate concrete. Constr Build Mater 2009;23:1287-91.

[3] Tsung YT, Yuen YC, Chao LH. Properties of HPC regates. Cem Concr Res 2006;36:943-50.

[4] How JC, Tsong Y, Kuan HC. Use of building rubbles as recycled aggregates. Cem Concr Res 2003;33:12532.

[5] Vivian WYT, Gao XF, Tam CM. Microstructural analysis of recycled aggregate concrete produced from two-stage mixing approach. Cem Concr Res 2005;35:1195-203.

[6] Ahmad S, Aimin X. Performance and properties of structural concrete made with recycled concrete aggregate. ACI Mater J 2003:371-80 [100-M42]. 